\title{
Tolerogenic effect of non-inherited maternal antigens in hematopoietic stem cell transplantation
}

\section{Masahiro Hirayama, Eiichi Azuma* and Yoshihiro Komada}

Department of Pediatrics and Cell Transplantation, Mie University Graduate School of Medicine, Tsu, Mie, Japan

\section{Edited by:}

Stephen Paul Cobbold, University of

Oxford, UK

\section{Reviewed by:}

Julian Dyson, Imperial College

London, UK

Bruce Milne Hall, University of New South Wales, Australia

*Correspondence:

Eiichi Azuma, Department of Pediatrics and Cell Transplantation, Mie University Graduate School of Medicine, 2-174 Edobashi, Tsu, Mie 514-8507, Japan. e-mail:

e-azuma@clin.medic.mie-u.ac.jp

\begin{abstract}
Major histocompatibility complex antigens that provoke severe transplant reactions are referred to as the human leukocyte antigen ( $\mathrm{HLA}$ ) in human and as the $\mathrm{H}-2$ in mice. Even if the donor and recipient are HLA-identical siblings, graft-versus-host reactions have been linked to differences in the minor histocompatibility antigen. As the chance of finding an HLA-identical sibling donor is only $25 \%$, attention has been focused on using alternative donors. An HLA-mismatched donor with non-inherited maternal antigens (NIMA) is less immunogenic than that with non-inherited paternal antigens, because the contact between the immune systems of the mother and child during pregnancy affects the immune response of the child against NIMA. However, the immunologic effects of developmental exposure to NIMA are heterogeneous, and can be either tolerogenic or immunogenic. We recently have devised a novel method for predicting the tolerogenic effect of NIMA. In this review, we overview the evidence for the existence of the NIMA tolerogenic effect, the possible cellular and molecular basis of the phenomenon, and its utilization in hematopoietic stem cell transplantation. We suggest a future direction for the safe clinical use of this phenomenon, fetomaternal tolerance, in the transplantation field.
\end{abstract}

Keywords: NIMA, tolerance, acute GVHD, hematopoietic stem cell transplantation

\section{INTRODUCTION}

More than 50 years ago, Owen etal. (1954) made the remarkable discovery that most twin cattle were born with a stable mixture of each other's red cells. Claas et al. (1988) later found that human leukocyte antigen (HLA) broadly sensitized patients commonly failed to produce antibodies against mismatched noninherited maternal antigens (NIMA), but were fully capable of producing anti-non-inherited paternal antigens (NIPA). The definition of NIMA or NIPA is based on an offspring-based HLA haplotype that is not inherited from the mother or father, respectively. Billingham etal. (1953) then showed that injection of allogeneic splenocytes from murine fetuses enabled the acceptance of later skin grafts from the same donor. This phenomenon is now referred to as fetomaternal tolerance, and suggests that perinatal exposure to NIMA may affect the developing immune system of neonates. These phenomena have been clinically utilized in organ transplantation and allogeneic hematopoietic stem cell transplantation (HSCT; Burlingham et al., 1998; van Rood et al., 2002). Burlingham et al. (1998) showed the superior graft survival rate in NIMA- compared to NIPA-mismatched renal transplant recipients from sibling donors. Furthermore, van Rood et al. (2002) demonstrated that HSCT from NIMA-mismatched sibling donors showed a lower incidence of severe acute graft-versushost disease (GVHD) compared with that from the other family donors. Ichinohe et al. (2004) have demonstrated the feasibility of HLA-haploidentical HSCT from NIMA-mismatched relatives without $\mathrm{T}$ cell depletion. These clinical studies have been performed based on the presence of fetomaternal microchimerism as a result of fetomaternal immunological tolerance. Nevertheless, some cases developed severe acute GVHD despite the existence of microchimeric cells (Kanda et al., 2009). We recently reported that NIMA effects directed toward the major histocompatibility complex (MHC) antigen were divided into immunogenic and tolerogenic reactivities (Araki et al., 2010). These effects were correlated with maternal microchimerism. The reactivities were predictable by an MLR-ELISPOT (mixed lymphocyte reaction; enzyme linked immunospot) assay. We found that non-T cell-depleted (TCD) NIMA-mismatched haploidentical HSCT could be performed safely by evaluating the reaction of IFN- $\gamma$-producing cells of the donors against NIMA before transplantation.

\section{HISTOCOMPATIBILITY ANTIGENS IN HUMANS AND MICE}

Alloantigens can be divided into MHC antigen and minor histocompatibility antigen (MiHA), the former being responsible for eliciting the strongest immune responses to allogeneic tissues. The MHC is referred to as the HLA complex in humans and as the H-2 complex in mice (Table 1). The genes related to the HLA system encode a complex array of histocompatibility molecules that play a central role in immune responsiveness and in determining the outcome of HSCT in humans (Beatty et al., 1993; Petersdorf et al., 1995). The primary goal of histocompatibility testing for patients who are undergoing HSCT is the identification of a suitable HLA-matched donor to reduce the risk of post-transplant complications, which may result from HLA incompatibility.

The MHC identity of the donor and host is not the sole factor determining the immunological reactivity in HSCT. When transplantation is performed in an unrelated setting, even if the MHC antigens of donor are identical to those of recipient, considerable transplant reactions may occur because of differences 
Table 1 | Histocompatibility antigens in humans and mice.

\begin{tabular}{lll}
\hline & Human & Mouse \\
\hline MHC antigen & & \\
Class I & A, B, C & K, D, L \\
Class II & DR, DQ, DP & IA, IE \\
MiHA & & \\
Y chromosome & SMCY, UTY, DBY, DFFRY, & HY (Smcy), HY (Uty), \\
\multicolumn{1}{c}{ related } & RPS4Y, TMSB4Y & HY (Dby) \\
Autosomal & HA-1, HA-2, HA-3, HA-8, HB-1, & H3, H4, H7, H13, \\
chromosome & ACC-1, ACC-2, UGT2B17, LRH-1, & H28, H46, H47, H60 \\
related & CTSH, ECGF1, PANE1, SP110, & \\
& SLC1A5, SLC19A1, P2RX7 & \\
\hline
\end{tabular}

at various minor histocompatibility loci. MiHAs, peptides derived from polymorphic proteins, are capable of eliciting cellular alloimmune responses in vitro and in vivo. Their immunogenicity arises as a result of their presentation in the context of MHC class I or II, where they are recognized by alloreactive MHC-restricted $\mathrm{T}$ cells. The most important immune reactions elicited by in vivo alloreactivity to MiHA are graft rejection and acute GVHD.

To date, human MiHAs have not been fully characterized, although some murine MiHAs have been compared with the human counterparts (Table 1). Immunological targeting of HY proteins results in a relatively high incidence of acute GVHD when male recipients receive HSCT from female donors (Stern et al., 2006). While approximately one-third of the known MiHAs are encoded on the Y chromosome, many MiHAs are located on autosomal chromosomes. A genetic linkage analysis has been used to define the genomic regions encoding the MiHAs (Akatsuka et al., 2003; de Rijke et al., 2005). With the recent introduction of more advanced analytical techniques, more human MiHA epitopes have been identified (Van Bergen et al., 2010; Sellami et al., 2011).

\section{CLINICAL SIGNIFICANCE OF NON-INHERITED MATERNAL ANTIGEN}

Graft survival in HSCT is optimal when the donor and recipient are HLA-identical. However, in some situations, if this is not possible, haploidentical siblings, parents, and offspring are considered as potential donors. Contact between the mother and child during pregnancy can lead to tolerization, and subsequently have an additional benefit on the transplant outcome. A new nomenclature was proposed to assign the haplotypes of a family in which one of the siblings is a potential transplant donor (van Rood and Claas, 2000) as depicted in Figure 1. The parents or siblings that share one haplotype with the recipient and differ for the other haplotype are potential donors. The patient inherits the inherited maternal HLA antigens (IMA) haplotype from the mother, and the inherited paternal HLA antigens (IPA) from the father. When the patient is transplanted from one of the parents or from a haploidentical sibling, the NIMA or NIPA is the mismatched haplotype. This nomenclature scheme can also be used in cases where the mother or father is the potential donor (Figure 1).

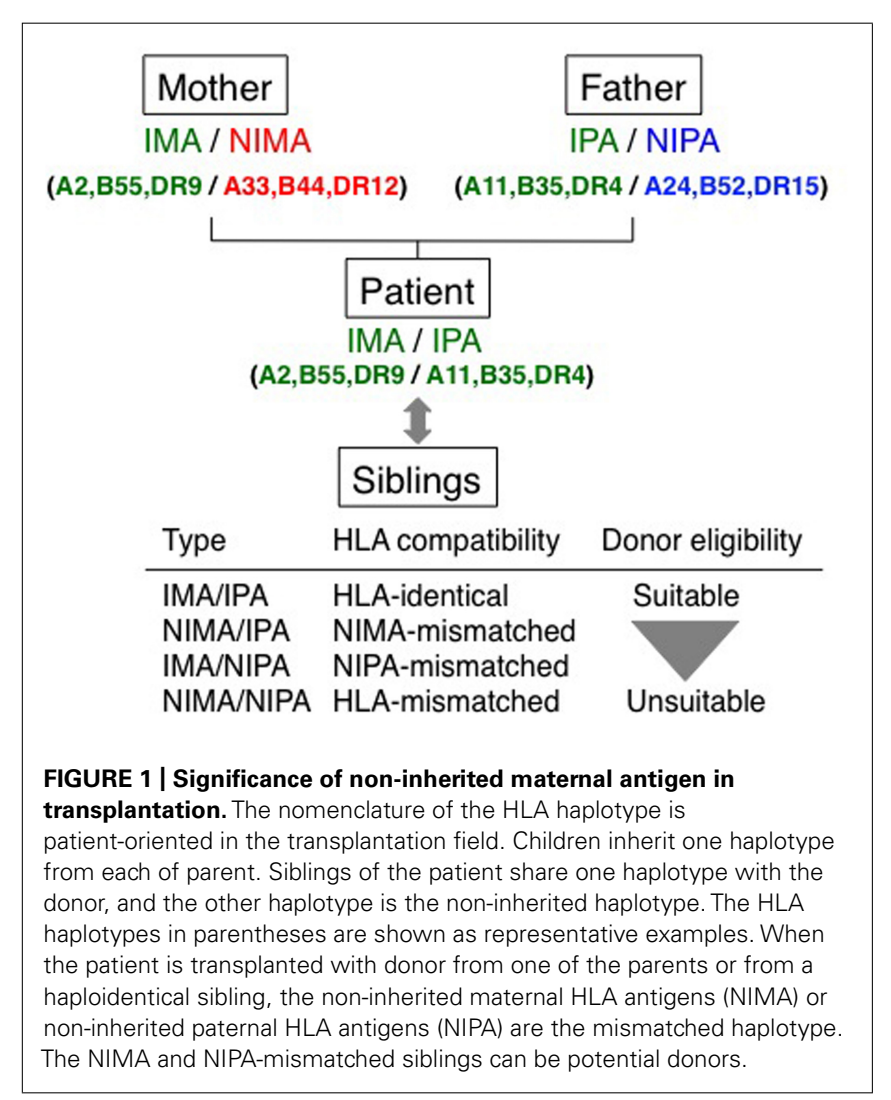

Because of the existence of fetomaternal tolerance, NIPA is more immunogenic than NIMA. Therefore, the order of donor eligibility is IMA/IPA, NIMA/IPA followed by IMA/NIPA.

Several studies have been performed to investigate the influence of non-inherited and inherited parental antigens on transplantation, and tolerizing effects (a NIMA effect) have been described. In HSCT, van Rood et al. (2002) and Ichinohe et al. (2004) showed that the patients who received non-TCD BMT from a NIMAmismatched donor had a significantly lower incidence of acute GVHD than a NIPA-mismatched donor. However, even in nonTCD BMT from a NIMA-mismatched donor, $10 \%$ of patients still experienced severe acute GVHD (Ichinohe et al., 2004). Furthermore, graft rejection and hyperacute GVHD after HSCT from NIMA-mismatched siblings have been observed in spite of the fact that maternal microchimerism was detected (Okumura et al., 2007). On the other hand, Kanda et al. (2009) described that a substantial proportion of long-term survivors after NIMAmismatched HSCT could discontinue the administration of immunosuppressive agents, despite the frequent occurrence of moderate to severe chronic GVHD. Therefore, a method that could evaluate this unpredictable NIMA effect was desired.

\section{MURINE MODELS FOR MAJOR AND MINOR HISTOCOMPATIBILITY ANTIGENS TO NIMA}

There have been several investigations of NIMA in murine models (Burlingham et al., 1998; Andrassy et al., 2003). The immunological effects of developmental exposure to NIMA are heterogeneous (Mold et al., 2008; Molitor-Dart et al., 2008; Verhasselt et al., 2008). 
The precise mechanisms underlying the heterogeneity are still under investigation. The relevance of MiHA in the NIMA effect has not been reported. Not only in the MHC-identical, but also under MHC-haploidentical conditions, MiHA alloreactivities may be induced upon transplantation (Verdijk et al., 2004). Therefore, focusing on the NIMA effect separated by the MHC (H-2) and MiHA responses is clinically relevant.

The mouse MiHA loci confer a wide range of immunogenicity, ranging from weakly to strongly immunogenic (Table 1; Mendoza et al., 1997; Choi et al., 2001; Roopenian et al., 2002). Recent studies have provided evidence that GVHD could be caused by a limited number of MiHA, including H4, H7, H13, H28, H60, and H-Y (Eden et al., 1999; Choi et al., 2002; Yang et al., 2003). The immunodominance of these MiHA was manifested on genetically varied backgrounds among B10, BALB/c, and DBA/2 strains (Sanderson and Frost, 1974; Mendoza et al., 1997; Malarkannan et al., 2000). So far, there has been no report distinguishing H-2 from MiHA with regard to NIMA. We have classified mouse models of NIMA based on the major and minor histocompatibility antigens to NIMA (Hirayama and Azuma, 2011). In our study, B10 congenic mice were used as NIMA models and the MiHA matched entirely in this system (Figure 2B). On the other hand, in the conventional model (Figure 2A), the NIMA includes not only non-inherited $\mathrm{H}-2$, but also non-inherited MiHA. Therefore,

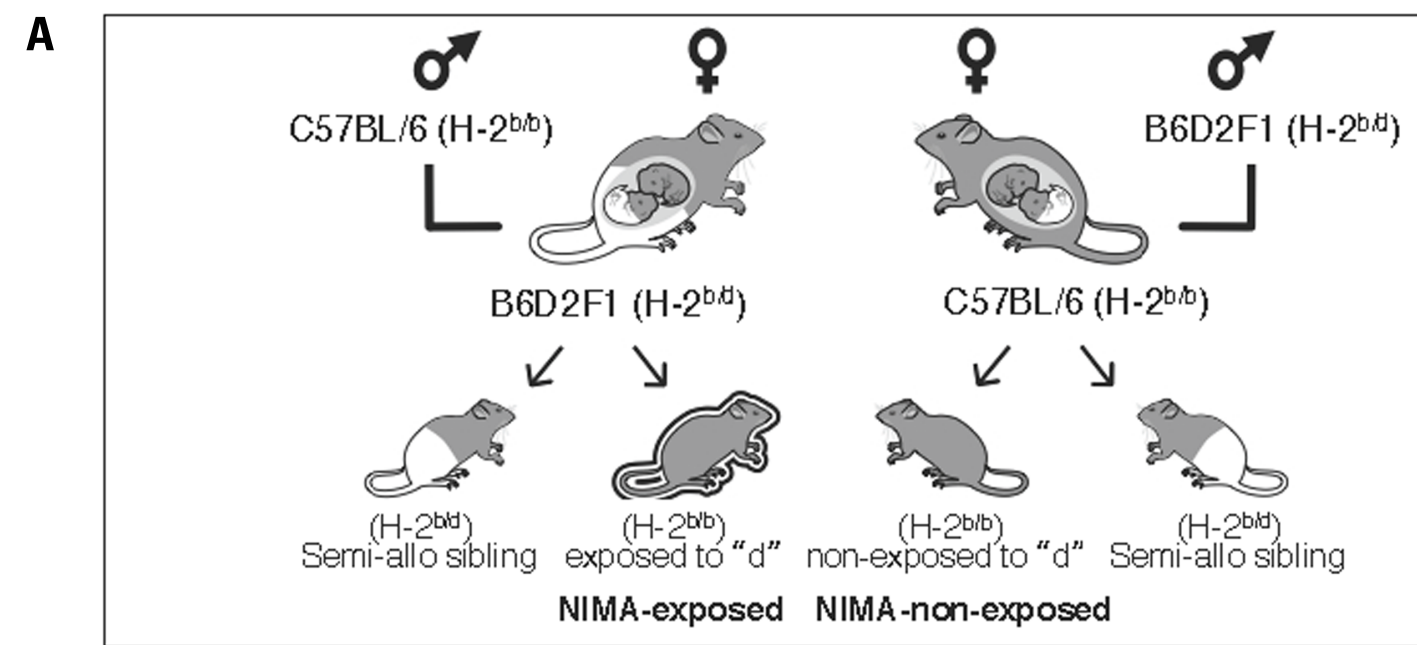

Modified from Andrassy et al. (2003)

B

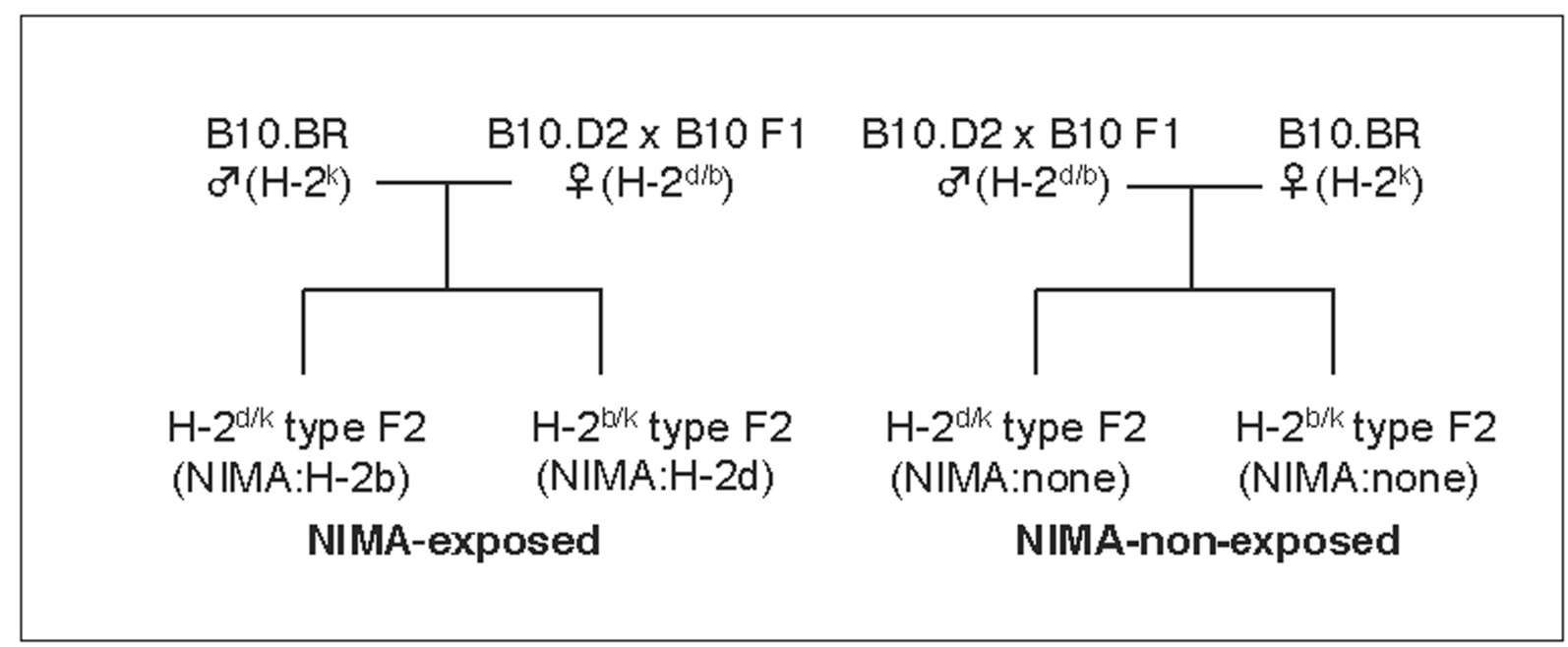

Araki et al. (2010)

FIGURE 2 | Murine models for non-inherited maternal antigens. (A) Left, C57BL/6 (B6) males $\left(\mathrm{H}-2^{\mathrm{b} / \mathrm{b}}\right)$ were mated with $(\mathrm{B} 6 \times \mathrm{DBA} / 2) \mathrm{F} 1$ females $\left(\mathrm{H}-2^{\mathrm{b} / \mathrm{d}}\right)$, thus exposing the $\mathrm{H}-2^{\mathrm{b} / \mathrm{b}}$ offspring in utero and via breastfeeding to NIMAd antigens. Right, $(\mathrm{B} 6 \times \mathrm{DBA} / 2) \mathrm{F} 1$ males were mated with $\mathrm{B} 6$ females, creating $\mathrm{H}-2^{\mathrm{b} / \mathrm{b}}$ backcross offspring that had not been exposed to "d," as reported by Andrassy et al. (2003). (B) Left, B10.BR males $\left(\mathrm{H}-2^{k}\right)$ were mated with (B10.D2 $\times$ B10) F1 females $\left(H-2^{d / b}\right)$, thus exposing the $\mathrm{H}-2^{\mathrm{d} / \mathrm{k}}$ type offspring to $\mathrm{NIMA}$, and $\mathrm{H}-2^{\mathrm{b} / \mathrm{k}}$ type offspring to NIMA ${ }^{d}$. Right, (B10.D2 × B10) F1 males $\left(\mathrm{H}-2^{\mathrm{d} / \mathrm{b}}\right)$ were mated with B10.BR females $\left(\mathrm{H}-2^{\mathrm{k}}\right)$, creating the controls; both $\mathrm{H}-2^{\mathrm{d} / \mathrm{k}}$ and $\mathrm{H}-2^{\mathrm{b} / \mathrm{k}}$ type offspring that had not been exposed to " $\mathrm{b}$ " and " $\mathrm{d}$," respectively. These mice have a B10 background, in other words, their $\mathrm{MiHA}$ are matched, and the $\mathrm{H}-2$ antigens are mismatched for both class I and II. 
our NIMA model, but not the conventional NIMA model, did not affect the immunogenicity of MiHA. We examined the tolerogenic potential of NIMA-exposure for $\mathrm{H}-2$ of class I and II disparities without any influences of the MiHA (Araki et al., 2010). Contrary to previous reports that showed an apparent NIMA effect (Andrassy et al., 2003; Aoyama etal., 2009), we found no evidence of the NIMA effect (Araki et al., 2010). The reason for the difference remains to be determined, but it could be due to the abrogation of the MiHA effect in our system (Figure 2B).

\section{MATERNAL MICROCHIMERISM AND FETOMATERNAL TOLERANCE}

The bidirectional exchange of cells, both mature and progenitor types, at the maternal-fetal interface is a common feature of mammalian reproduction (Lo et al., 1996). The presence of semiallogeneic cells in a host can have significant immunological effects on transplantation tolerance and rejection. Maternal cells and DNA were detected for a long time after parturition in the peripheral blood and lymphoid organs of offspring (Maloney et al., 1999; Andrassy et al., 2003). Breastfeeding during the neonatal period also might contribute to building-up maternal microchimerism in the offspring, because breast milk is rich in soluble maternal MHC antigens (Verhasselt et al., 2008; Aoyama et al., 2009). Maternal microchimerism may cause tolerance, resulting in the acceptance of an allograft bearing antigens shared by the microchimeric cells. However, microchimerism may also cause sensitization, thus resulting in rejection. Distinguishing which of these effects is likely to occur prior to the transplant may revolutionize the field of living-related renal transplantation, wherein microchimerism can exert a powerful influence on graft outcome (van Rood et al., 2002). Long-term maternal microchimerism is easily detected from the peripheral blood or various tissues, including the skin, liver, and thyroid gland, by using highly sensitive polymerase chain reaction-based techniques (Ichinohe et al., 2002). Although many investigators have suggested the association of long-term maternal and fetal microchimerism with the development of autoimmune diseases, including systemic sclerosis, primary biliary cirrhosis, juvenile inflammatory myopathies, and biliary atresia (Nelson, 2003; Suskind et al., 2004), it is difficult to establish a precise etiological link, because maternal microchimerism is frequently found in healthy females with a history of uncomplicated pregnancy, and in more than two-thirds of immunocompetent individuals without any manifestations of autoimmune attacks (Kodera et al., 2005). Moreover, Ko et al. (1999) suggested that passenger leukocytes were involved in the induction phase of allograft acceptance and microchimerism in the thymus, but not in the blood, and were also associated with allograft survival. These results suggest that microchimerism may play a role in allograft survival, but that the persistence of peripheral microchimerism is not required.

Several mechanisms of fetomaternal tolerance have so far been reported. One possible mechanism is the clonal deletion of NIMAspecific lymphocytes. Vernochet et al. (2005) described partial deletion of B cells having high affinity for the NIMA. However, B cells having low affinity for the NIMA were not clonally deleted. Bemelman et al. (1998) showed central and peripheral deletion of donor-specific $\mathrm{T}$ cells after establishing mixed chimerism in the recipient with a high dose of bone marrow cells. Low doses of bone marrow cells induced a form of tolerance that was regulatory $\mathrm{T}$ cells (Treg)-dependent, consistent with the establishment of microchimerism rather than mixed chimerism. Bonilla et al. (2006) described that deletion of effector T cells due to a form of suppressive microchimerism in antigen-presenting cells was a consequence of the establishment of a dominant Treg-population in the host. Therefore, fetomaternal tolerance could not be explained only by the clonal deletion mechanism.

Another possible mechanism is the induction of Treg for NIMA. Tsang et al. (2008) described the possibility of inducing NIMA-specific Treg in the direct and indirect presentation of maternal microchimerism. On the other hand, since oral tolerance is known to generate TGF- $\beta$-producing Treg (Gonnella et al., 2003), oral exposure to maternal MHC antigens present in breast milk (Molitor et al., 2004) may generate NIMA-specific Treg, which may prevent the deletion of maternal cells by NIMAspecific effector T cells, resulting in a high level of microchimerism. Aoyama et al. (2009) reported that exposure to NIMA both in utero and by breastfeeding appears to generate higher levels of maternal microchimerism than in utero exposure alone, and that the degree of microchimerism, correlates with a prolonged survival in maternal heart grafts.

\section{PREDICTION OF ACUTE GVHD IN HLA-MISMATCHED HSCT}

Predicting acute GVHD in vitro before transplantation has been tried in an HLA-mismatched setting, but satisfactory methods had not been established. The frequencies of cytotoxic T lymphocyte precursor (CTLp) and helper T lymphocyte precursor (HTLp) cells, as well as MLR, were reported for the methods that had been evaluated to detect an individual's reactivity to NIMA in vitro (Falkenburg et al., 1996; Moretta et al., 1999; Tsafrir et al., 2000). Moretta et al. (1999) described that the frequency of NIMAspecific CTLp in cord blood samples could be measured in order to better define the phenomenon of NIMA tolerance. NIMA-reactive cord blood cells were detectable, but the authors of that study could not show a difference in the CTLp frequency toward NIMA and NIPA. Falkenburg et al. (1996) investigated whether NIMA tolerance could allow transplantation over certain HLA barriers. Neither the CTLp nor HTLp frequencies against NIPA were not significantly different from those against NIMA. Indeed, Kircher et al. (2004) showed that the CTLp and HTLp frequencies were not predictive for the risk of acute GVHD in patients who received allogeneic HSCT. Collectively, established test systems are not available for predicting an alloreaction and the outcome after HSCT. CTLp reflects the alloreactivity of class I mismatch, and MLR and HTLp reflect alloreactivity of class II mismatch. Levitsky et al. (2009) reported an evaluation of allogeneic reactions that used Treg. They generated carboxyfluorescein diacetate succinimidyl ester-labeled $\mathrm{CD} 4{ }^{+} \mathrm{CD} 25^{\text {high }} \mathrm{FOXP}^{+}$cells in MLR, which they called "Treg MLR," with varying HLA disparities and cell components. However, this method reflects only differences in MHC class II. Thus, all of the above-mentioned methods can detect MHC class I or class II separately, but it is difficult to detect them simultaneously (Table 2). We recently, reported a novel method, MLR-ELISPOT assay, that overcomes these disadvantages, as shown in Figure 3A.

The alloreactivities of NIMA-exposed mice and NIMA-nonexposed mice were evaluated by MLR, and we found a wide range 
Table 2 | Assays to detect allogeneic antigens.

\begin{tabular}{ll}
\hline Assay & Target antigen \\
\hline Frequency of cytotoxic T lymphocyte precursor & MHC class I \\
Frequency of helper T Iymphocyte precursor & MHC class II \\
Mixed lymphocyte reaction (MLR), modified MLR & MHC class II \\
Regulatory T Iymphocyte MLR & MHC class II \\
MLR-ELISPOT for interferon- $\gamma$ & MHC class I and II \\
\end{tabular}
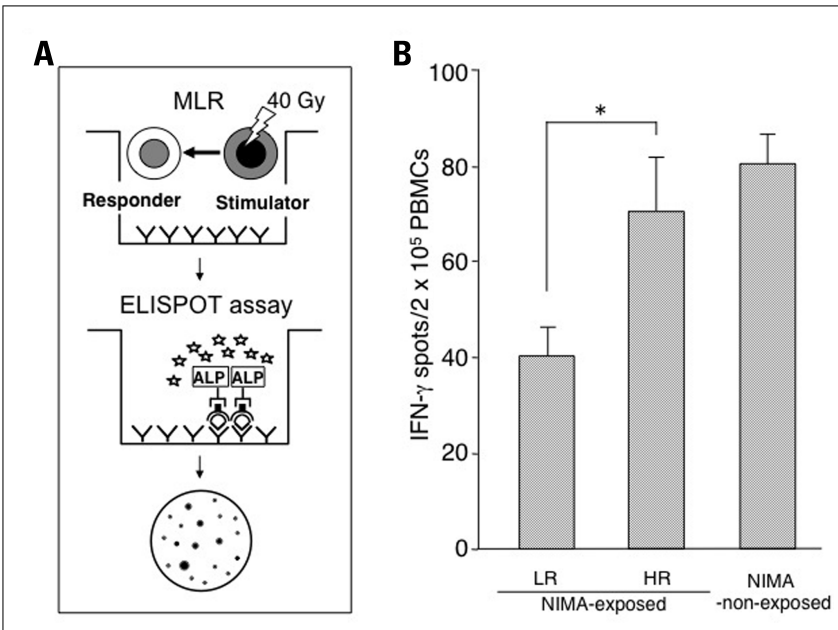

FIGURE 3 | Prediction of the reactivity to NIMA by the MLR-ELISPOT assay. (A) The ELISPOT assay combined with MLR (MLR-ELISPOT) is a sensitive functional assay to detect alloreactivity for both major and minor histocompatibility antigens in mice. (B) The mice were classified into two groups based on their reactivity to NIMA; the high responders ( $\mathrm{HR} \geq$ mean $\pm 1 \mathrm{SD}$ in NIMA-non-exposed) or the low responders (LR < mean \pm 1 SD) group by using MLR (Araki et al., 2010). The IFN- $\gamma$-producing ability before the induction of GVHD was presented by the MLR-ELISPOT assay. Peripheral blood mononuclear cells from NIMA-exposed LR mice $(n=8)$, NIMA-exposed HR mice $(n=7)$, and non-exposed mice $(n=6)$ were stimulated with B10 mouse peripheral blood mononuclear cells. The data are expressed as the means \pm SD of individual animals. ${ }^{*} p<0.05$.

\section{REFERENCES}

Akatsuka, Y., Nishida, T., Kondo, E., Miyazaki, M., Taji, H., Iida, H., Tsujimura, K., Yazaki, M., Naoe, T., Morishima, Y., Kodera, Y., Kuzushima, K., and Takahashi, T. (2003). Identification of a polymorphic gene, BCL2A1, encoding two novel hematopoietic lineage-specific minor histocompatibility antigens. J. Exp. Med. 197, 1489-1500.

Andrassy, J., Kusaka, S., Jankowska-Gan, E., Torrealba, J. R., Haynes, L. D., Marthaler, B. R., Tam, R. C., Illigens, B. M., Anosova, N., Benichou, G.,

of reactivity (Araki et al., 2010). This indicates that the fetomaternal interaction acts on both tolerance (low-responder, LR) and sensitization (high-responder, HR; Molitor-Dart et al., 2008; van Halteren et al., 2009). The reports from Falkenburg et al. (1996) and Tsafrir et al. (2000) detected a reactivity to NIMA by MLR, and CTLp and HTLp, respectively. Interestingly, when we scrutinized the figures in their articles, the individual reactivities of the NIMA-exposed group showed a wider range than the control group, and those reactivities seem to be divided into low and high reactions, although the authors of those studies did not discuss these observations. This was a further indication that reactivity to NIMA could be detected in vitro, and that the fetomaternal interaction promoted either tolerance or sensitization.

Recently, we demonstrated that the number of cells producing IFN- $\gamma$ was significantly lower in the NIMA-exposed LR group than the HR group by using an MLR-ELISPOT assay in a murine model (Figure 3B). Thus, the capacity for an individual to produce IFN- $\gamma$ against allogeneic antigens or NIMA could differentiate LR from HR. This assay is easily applicable in humans, and is a versatile method to detect reactivities to MHC class I, as well as class II. Moreover, its detection may reflect the reactivity to MiHA. In other words, this assay might be useful to predict the total immunological reaction of donor $\mathrm{T}$ cells to the recipient in HLA-mismatched HSCT.

\section{CONCLUSION}

Non-inherited maternal antigens-mismatched haploidentical HSCT has been progressing, and now can lead to sustained engraftment, lower early treatment-related mortality, and acceptable rates of acute GVHD. However, it is difficult to predict severe acute GVHD prior to transplantation. Our recent report addressed this issue (Araki et al., 2010). The NIMA effect directed toward MHC antigens was divided into immunogenic and tolerogenic reactivities. There was an unevenness in the acquisition and maintenance of microchimerism in offspring, which was not due solely to differences in MHC gene inheritance. Although T cell replete haploidentical transplantation is performed only when there is positive microchimerism, the individual reactivity of the donor is not evaluated at present. Therefore, our study is clinically relevant, and T cell replete NIMA-mismatched haploidentical transplantation can be performed more safely in the future by evaluating the responses of the IFN- $\gamma$-producing cells of the donor against NIMA.

Y. (2010). Prediction of reactivity to noninherited maternal antigen in MHC-mismatched, minor histocompatibility antigen-matched stem cell transplantation in a mouse model. $J$. Immunol. 185, 7739-7745.

Beatty, P. G., Anasetti, C., Hansen, J. A., Longton, G. M., Sanders, J. E., Martin, P. J., Mickelson, E. M., Choo, S. Y., Petersdorf, E. W., Pepe, M. S., Appelbaum, F. R., Bearman, S. I., Buckner, C. D., Clift, R. A., Petersen, F. B., Singer, J., Stewart, P. S., Storb, R. F., Sullivan, K. M., Tesler, M. C., Witherspoon, R. P., and Thomas,
E. D. (1993). Marrow transplantation from unrelated donors for treatment of hematologic malignancies: effect of mismatching for one HLA locus. Blood 81, 249-253.

Bemelman, F., Honey, K., Adams, E. Cobbold, S., and Waldmann, $\mathrm{H}$. (1998). Bone marrow transplantation induces either clonal deletion or infectious tolerance depending on the dose. J. Immunol. 160, 2645-2648.

Billingham, R. E., Brent, L., and Medawar, P. B. (1953). Actively acquired tolerance of foreign cells. Nature 172, 603-606. 
Bonilla, W. V., Geuking, M. B., Aichele, P., Ludewig, B., Hengartner, H., and Zinkernagel, R. M. (2006). Microchimerism maintains deletion of the donor cell-specific CD8+ T cell repertoire. J. Clin. Invest. 116, 156-162.

Burlingham, W. J., Grailer, A. P., Heisey, D. M., Claas, F. H., Norman, D., Mohanakumar, T., Brennan, D. C., de Fijter, H., van Gelder, T., Pirsch, J. D., Sollinger, H. W., and Bean, M. A. (1998). The effect of tolerance to noninherited maternal HLA antigens on the survival of renal transplants from sibling donors. N. Engl. J. Med. 339, 1657-1664.

Choi, E. Y., Christianson, G. J., Yoshimura, Y., Jung, N., Sproule, T. J., Malarkannan, S., Joyce, S., and Roopenian, D. C. (2002). Realtime T-cell profiling identifies $\mathrm{H} 60$ as a major minor histocompatibility antigen in murine graft-versus-host disease. Blood 100, 4259-4265.

Choi, E. Y., Yoshimura, Y., Christianson, G. J., Sproule, T. J., Malarkannan, S., Shastri, N., Joyce, S., and Roopenian, D. C. (2001). Quantitative analysis of the immune response to mouse non-MHC transplantation antigens in vivo: the $\mathrm{H} 60$ histocompatibility antigen dominates over all others. $J$. Immunol. 166, 4370-4379.

Claas, F. H., Gijbels, Y., van der Veldende Munck, J., and van Rood, J. J. (1988). Induction of B cell unresponsiveness to noninherited maternal HLA antigens during fetal life. Science 241, 1815-1817.

de Rijke, B., van Horssen-Zoetbrood, A., Beekman, J. M., Otterud, B., Maas, F., Woestenenk, R., Kester, M., Leppert, M., Schattenberg, A. V., de Witte, T., van de Wielvan Kemenade, E., and Dolstra, H. (2005). A frameshift polymorphism in P2X5 elicits an allogeneic cytotoxic $\mathrm{T}$ lymphocyte response associated with remission of chronic myeloid leukemia. J. Clin. Invest. 115, 35063516.

Eden, P. A., Christianson, G. J., Fontaine, P., Wettstein, P. J., Perreault, C., and Roopenian, D. C. (1999). Biochemical and immunogenetic analysis of an immunodominant peptide (B6dom1) encoded by the classical $\mathrm{H} 7$ minor histocompatibility locus. J. Immunol. 162, 45024510.

Falkenburg, J. H., van LuxemburgHeijs, S. A., Lim, F. T., Kanhai, H. H., and Willemze, R. (1996). Umbilical cord blood contains normal frequencies of cytotoxic T-lymphocyte precursors (ctlp) and helper T-lymphocyte precursors against noninherited maternal antigens and noninherited paternal antigens. Ann. Hematol. 72, 260-264.

Gonnella, P. A., Kodali, D., and Weiner, H. L. (2003). Induction of low dose oral tolerance in monocyte chemoattractant protein-1- and CCR2-deficient mice. J. Immunol. 170, 2316-2322.

Hirayama, M., and Azuma, E. (2011). Major and minor histocompatibility antigens to NIMA: prediction of a tolerogenic NIMA effect. Chimerism 2, 23-24.

Ichinohe, T., Maruya, E., and Saji, H. (2002). Long-term feto-maternal microchimerism: nature's hidden clue for alternative donor hematopoietic cell transplantation? Int. J. Hematol. 76, 229-237.

Ichinohe, T., Uchiyama, T., Shimazaki, C., Matsuo, K., Tamaki, S., Hino, M., Watanabe, A., Hamaguchi, M., Adachi, S., Gondo, H., Uoshima, N., Yoshihara, T., Hatanaka, K., Fujii, H., Kawa, K., Kawanishi, K., Oka, K., Kimura, H., Itoh, M., Inukai, T., Maruya, E., Saji, H., Kodera, Y., and Japanese Collaborative Study Group for NIMA-Complementary Haploidentical Stem Cell Transplantation. (2004). Feasibility of HLA-haploidentical hematopoietic stem cell transplantation between noninherited maternal antigen (NIMA)-mismatched family members linked with long-term fetomaternal microchimerism. Blood 104, 3821-3828.

Kanda, J., Ichinohe, T., Shimazaki, C., Hamaguchi, M., Watanabe, A., Ishida, H., Yoshihara, T., Morimoto, A., Uoshima, N., Adachi, S., Inukai, T., Sawada, A., Oka, K., Itoh, M., Hino, M., Maruya, E., Saji, H., Uchiyama, T., and Kodera, Y. (2009). Long-term survival after HLA-haploidentical SCT from noninherited maternal antigenmismatched family donors: impact of chronic GVHD. Bone Marrow Transplant. 44, 327-329.

Kircher, B., Niederwieser, D., Gächter, A., Lätzer, K., Eibl, G., Gastl, G., and Nachbaur, D. (2004). No predictive value of cytotoxic or helper T-cell precursor frequencies for outcome when analyzed from the graft after stem cell transplantation. Ann. Hematol. 83, 566-572.

Ko, S., Deiwick, A., Jäger, M. D., Dinkel, A., Rohde, F., Fischer, R., Tsui, T. Y., Rittmann, K. L., Wonigeit, K., and Schlitt, H. J. (1999). The functional relevance of passenger leukocytes and microchimerism for heart allograft acceptance in the rat. Nat. Med. 5 , 1292-1297.
Kodera, Y., Nishida, T., Ichinohe, T., and Saji, H. (2005). Human leukocyte antigen haploidentical hematopoietic stem cell transplantation: indications and tentative outcomes in Japan. Semin. Hematol. 42, 112-118.

Levitsky, J., Miller, J., Leventhal, J., Huang, X., Flaa, C., Wang, E., Tambur, A., Burt, R. K., Gallon, L., and Mathew, J. M. (2009). The human "Treg MLR": immune monitoring for FOXP3 $+\mathrm{T}$ regulatory cell generation. Transplantation 88, 1303-1311.

Lo, Y. M., Lo, E. S., Watson, N., Noakes, L., Sargent, I. L., Thilaganathan, B., and Wainscoat, J. S. (1996). Twoway cell traffic between mother and fetus: biologic and clinical implications. Blood 88, 4390-4395.

Malarkannan, S., Horng, T., Eden, P., Gonzalez, F., Shih, P., Brouwenstijn, N., Klinge, H., Christianson, G., Roopenian, D., and Shastri, N. (2000). Differences that matter: major cytotoxic $\mathrm{T}$ cell-stimulating minor histocompatibility antigens. Immunity 13, 333-344.

Maloney, S., Smith, A., Furst, D. E., Myerson, D., Rupert, K., Evans, P. C., and Nelson, J. L. (1999). Microchimerism of maternal origin persists into adult life. J. Clin. Invest. 104, 41-47.

Mendoza, L. M., Paz, P., Zuberi, A., Christianson, G., Roopenian, D., and Shastri, N. (1997). Minors held by majors: the H13 minor histocompatibility locus defined as a peptide/MHC class I complex. Immunity 7 , 461-472.

Mold, J. E., Michaëlsson, J., Burt, T. D., Muench, M. O., Beckerman, K. P., Busch, M. P., Lee, T. H., Nixon, D. F., and McCune, J. M. (2008). Maternal alloantigens promote the development of tolerogenic fetal regulatory $\mathrm{T}$ cells in utero. Science 322 , 1562-1565.

Molitor, M. L., Haynes, L. D., Jankowska-Gan, E., Mulder, A., and Burlingham, W. J. (2004). HLA class I noninherited maternal antigens in cord blood and breast milk. Hum. Immunol. 65, 231-239.

Molitor-Dart, M. L., Andrassy, J., Haynes, L. D., and Burlingham, W. J. (2008). Tolerance induction or sensitization in mice exposed to noninherited maternal antigens (NIMA). Am. J. Transplant. 8, 2307-2315.

Moretta, A., Locatelli, F., Mingrat, G., Rondini, G., Montagna, D. Comoli, P., Gandossini, S., Montini, E., Labirio, M., and Maccario, R. (1999). Characterisation of CTL directed towards non-inherited maternal alloantigens in human cord blood. Bone Marrow Transplant. 24, 1161-1166.

Nelson, J. L. (2003). Microchimerism in human health and disease. Autoimmunity 36, 5-9.

Okumura, H., Yamaguchi, M., Kotani, T., Sugimori, N., Sugimori, C., Ozaki, J., Kondo, Y., Yamazaki, H. Chuhjo, T., Takami, A., Ueda, M., Ohtake, S., and Nakao, S. (2007). Graft rejection and hyperacute graftversus-host disease in stem cell transplantation from non-inherited maternal-antigen-complementary HLA-mismatched siblings. Eur. J. Haematol. 78, 157-160.

Owen, R. D., Wood, H. R., Foord, A. G., Sturgeon, P., and Baldwin, L. G. (1954). Evidence for actively acquired tolerance to $\mathrm{Rh}$ antigens. Proc. Natl. Acad. Sci. U.S.A. 40, 420-424.

Petersdorf, E. W., Longton, G. M., Anasetti, C., Martin, P. J., Mickelson, E. M., Smith, A. G., and Hansen, J. A. (1995). The significance of HLADRB1 matching on clinical outcome after HLA-A, B, DR identical unrelated donor marrow transplantation. Blood 86, 1606-1613.

Roopenian, D., Choi, E. Y., and Brown, A. (2002). The immunogenomics of minor histocompatibility antigens. Immunol. Rev. 190, 86-94.

Sanderson, C. J., and Frost, P. (1974). The induction of tumour immunity in mice using glutaraldehyde-treated tumor cells. Nature 248, 690-691.

Sellami, M. H., Kaabi, H., Bibi, A., Sahli, C., Bani, M., Ben Ahmed, A., Massoud, T., and Hmida, S. (2011). Minor histocompatibility antigens in Tunisians: could platelet endothelial cell adhesion molecule 1 marker be one of them? Tissue Antigens 77, 68-73.

Stern, M., Passweg, J. R., Locasciulli, A., Socié, G., Schrezenmeier, H., Békássy, A. N., Fuehrer, M., Hows, J., Korthof, E. T., McCann, S., Tichelli, A., Zoumbos, N. C., Marsh, J. C., Bacigalupo, A., Gratwohl, A., and for the Aplastic Anemia Working Party of the European Group for Blood and Marrow Transplantation. (2006). Influence of donor/recipient sex matching on outcome of allogeneic hematopoietic stem cell transplantation for aplastic anemia. Transplantation $82,218-226$. Suskind, D. L., Rosenthal, P., Heyman, M. B., Kong, D., Magrane, G., BaxterLowe, L. A., and Muench, M. O. (2004). Maternal microchimerism in the livers of patients with biliary atresia. BMC Gastroenterol. 4, 14. doi: 10.1186/1471-230X-4-14

Tsafrir, A., Brautbar, C., Nagler, A., Elchalal, U., Miller, K., and Bishara, A. (2000). Alloreactivity of umbilical 
cord blood mononuclear cells: specific hyporesponse to noninherited maternal antigens. Hum. Immunol. $61,548-554$.

Tsang, J. Y.-S., Tanriver, Y., Jiang, S., Xue, S.-A., Ratnasothy, K., Chen, D., Stauss, H. J., Bucy, R. P., Lombardi, G., and Lechler, R. (2008). Conferring indirect allospecificity on $\mathrm{CD} 4{ }^{+} \mathrm{CD} 25^{+}$Tregs by TCR gene transfer favors transplantation tolerance in mice. J. Clin. Invest. 118, 3619-3628.

Van Bergen, C. A., Rutten, C. E., Van Der Meijden, E. D., Van LuxemburgHeijs, S. A., Lurvink, E. G., HouwingDuistermaat, J. J., Kester, M. G., Mulder, A., Willemze, R., Falkenburg, J. H., and Griffioen, M. (2010). Highthroughput characterization of 10 new minor histocompatibility antigens by whole genome association scanning. Cancer Res. 70, 90739083.

van Halteren, A. G., Jankowska-Gan, E., Joosten, A., Blokland, E., Pool, J., Brand, A., Burlingham, W. J., and Goulmy, E. (2009). Naturally acquired tolerance and sensitization to minor histocompatibility antigens in healthy family members. Blood 114, 2263-2272.

van Rood, J. J., and Claas, F. (2000). Both self and non-inherited maternal HLA antigens influence the immune response. Immunol. Today 21, 269-273.

van Rood, J. J., Loberiza, F. R. Jr., Zhang, M. J., Oudshoorn, M., Claas, F., Cairo, M. S., Champlin, R. E., Gale, R. P., Ringdén, O., Hows, J. M., and Horowitz, M. H. (2002). Effect of tolerance to noninherited maternal antigens on the occurrence of graft-versus-host disease after bone marrow transplantation from a parent or an HLA-haploidentical sibling. Blood 99, 1572-1577.

Verdijk, R. M., Kloosterman, A., Pool, J., van de Keur, M., Naipal, A. M., van Halteren, A. G., Brand, A., Mutis, T., and Goulmy, E. (2004). Pregnancy induces minor histocompatibility antigen-specific cytotoxic
$\mathrm{T}$ cells: implications for stem cell transplantation and immunotherapy. Blood 103, 1961-1964.

Verhasselt, V., Milcent, V., Cazareth, J. Kanda, A., Fleury, S., Dombrowicz, D., Glaichenhaus, N., and Julia, V. (2008). Breast milk-mediated transfer of an antigen induces tolerance and protection from allergic asthma. Nat. Med. 14, 170-175.

Vernochet, C., Caucheteux, S. M., Gendron, M. C., Wantyghem, J., and Kanellopoulos-Langevin, C. (2005). Affinity-dependent alterations of mouse B cell development by noninherited maternal antigen. Biol. Reprod. 72, 460-469.

Yang, J., Jaramillo, A., Liu, W. Olack, B., Yoshimura, Y., Joyce, S., Kaleem, Z., and Mohanakumar, T. (2003). Chronic rejection of murine cardiac allografts discordant at the $\mathrm{H} 13$ minor histocompatibility antigen correlates with the generation of the H13-specific CD8+ cytotoxic T cells. Transplantation 76 , 84-91.
Conflict of Interest Statement: The authors declare that the research was conducted in the absence of any commercial or financial relationships that could be construed as a potential conflict of interest.

Received: 15 March 2012; accepted: 10 May 2012; published online: 25 May 2012.

Citation: Hirayama M, Azuma $E$ and Komada Y (2012) Tolerogenic effect of non-inherited maternal antigens in hematopoietic stem cell transplantation. Front. Immun. 3:135. doi: 10.3389/ fimmu.2012.00135

This article was submitted to Frontiers in Immunological Tolerance, a specialty of Frontiers in Immunology.

Copyright (c) 2012 Hirayama, Azuma and Komada. This is an open-access article distributed under the terms of the Creative Commons Attribution Non Commercial License, which permits noncommercial use, distribution, and reproduction in other forums, provided the original authors and source are credited. 